\title{
Revisiting the Fact/Value Dichotomy: A Speech Act Approach to Improve the Integration of Ethics in Health Technology Assessment
}

\author{
Georges-Auguste Legault1,2*, Suzanne K.-Bédard2,3, Christian A. Bellemare ${ }^{2,3}$, \\ Jean-Pierre Béland ${ }^{2,4}$, Louise Bernier ${ }^{1}$, Pierre Dagenais ${ }^{2,3,5}$, Charles-Étienne Daniel1,2, \\ Hubert Gagnon², Monelle Parent ${ }^{2}$, Johane Patenaude ${ }^{2,5}$
}

${ }^{1}$ Faculté de droit, Université de Sherbrooke, Sherbrooke, Canada

${ }^{2}$ Institut interdisciplinaire d'innovation technologique (3IT) de l'Université de Sherbrooke, Sherbrooke, Canada

${ }^{3}$ Centre intégré universitaire de santé et services sociaux (CIUSSS) de l'Estrie-Centre hospitalier de l'université de Sherbrooke (CHUS), Sherbrooke, Canada

${ }^{4}$ Unité d'enseignement en éthique, Département des sciences humaines, Université du Québec à Chicoutimi (UQAC), Chicoutimi, Canada

${ }^{5}$ Faculté de médecine et des sciences de la santé de l'Université de Sherbrooke, Sherbrooke, Canada

Email: *Georges-Auguste.Legault@USherbrooke.ca, suzanne.kocsis-bedard.ciussse-chus@ssss.gouv.qc.ca,

Christian.Bellemare@USherbrooke.ca, jpbeland@uqac.ca, Louise.Bernier@USherbrooke.ca, Pierre.Dagenais@USherbrooke.ca, Charles-Etienne.Daniel@USherbrooke.ca, hubert.gagnon@usherbrooke.ca, Monelle.Parent@USherbrooke.ca,

Johane.Patenaude@USherbrooke.ca

How to cite this paper: Legault, G.-A., K.-Bédard, S., Bellemare, C. A., Béland, J.-P., Bernier, L., Dagenais, P., Daniel, C.-É., Gagnon, H., Parent, M., \& Patenaude J. (2018). Revisiting the Fact/Value Dichotomy: A Speech Act Approach to Improve the Integration of Ethics in Health Technology Assessment. Open Journal of Philosophy, 8, 578-593.

https://doi.org/10.4236/ojpp.2018.85042

Received: November 2, 2018

Accepted: November 27, 2018

Published: November 30, 2018

\begin{abstract}
Philosophers engaged in the field of applied ethics are often challenged to revisit certain philosophical debates in order to clarify the background concepts involved in a given undertaking at stake. This is particularly evident in the field of Health Technological Assessment (HTA) where the integration of ethics has been a debate for many years. Interdisciplinary technological assessment involves a head-on discussion between the frame of reference of natural sciences and those of philosophy, which often reproduce the fact/value dichotomy debated in the field of philosophy. The challenge for a philosopher is then to explain how the fact/value dichotomy has been criticized by philosophers in such a way that the distinction between "verifiable facts" and "unverifiable values" cannot be accounted for anymore. The critiques of H. Putnam and S. E. Toulmin were the first steps towards the understanding of the dichotomy. A speech act approach, based on J. L. Austin illocutionary acts, can shed a new light on this issue by clarifying the difference between assertions, evaluations and prescriptions. By using a speech-act approach we can define the respective role of scientific evaluation and ethical
\end{abstract}


Copyright $(0) 2018$ by authors and Scientific Research Publishing Inc. This work is licensed under the Creative Commons Attribution International License (CC BY 4.0).

http://creativecommons.org/licenses/by/4.0/ evaluation in the HTA process and offer a better guide for the decision-makers on all aspects of adopting a technological development in health.

\section{Keywords}

Fact/Value Dichotomy, Ethics, HTA, Health Technology Assessment

\section{Introduction}

Philosophers engaged in the field of applied ethics are often challenged to revisit certain philosophical debates in order to clarify the background concepts involved in a given undertaking at stake. The inevitable clash between background concepts of each of the disciplines involved has to be dealt within different institutional settings such as research ethics review boards (Legault, Patenaude, \& Parent, 2010), interdisciplinary research in nanotechnology (Patenaude et al., 2015), and responsible innovation teamwork (Legault, Verchères, \& Patenaude, 2018). Interdisciplinary technological assessment involves a head-on discussion between the frame of reference of natural sciences and those of philosophy, which often reproduces the fact/value dichotomy debated in the field of philosophy. This is particularly evident in the field of Health Technological Assessment (HTA) where the integration of ethics has been a debate for many years.

The fundamental role of the numerous HTA organizations around the world is to guide decision-making on the use of effective health technologies. Health Technology Assessment international (HTAi) is a scientific and professional society that regroups some 82 HTA organizations throughout the world involved in the production of these assessments (HTAi, 2018). The World Health Organization defines the HTA process as: “(...) the systematic evaluation of properties, effects, and/or impacts of health technology. It is a multidisciplinary process to evaluate the social, economic, organizational and ethical issues of a health intervention or health technology. The main purpose of conducting an assessment is to inform a policy decision-making" (WHO-HTA, 2017). Although the EUnetHTA's core model considers ethics as an important domain of HTA on its own (European Network for Health Technology Assessment EUnetHTA, 2014), there is still a lot to be done for ethics to be fully integrated into the HTA process. In her research on barriers and facilitators of ethical evaluation in HTA, Assasi et al. identified one major barrier as follows: "While we believe no conflict exists between technical and ethical concerns, we acknowledge that HTA producers with clinical or economic research backgrounds tend to subscribe to a distinction between empirically 'verifiable' facts and 'unverifiable' normative aspects or value judgments; and because ethics is often understood to be exclusively a normative domain, they might be reluctant to incorporate ethical aspects of healthcare technologies into their assessments" (Assasi, Schwartz, Tarride, O'Reilly, \& Goeree, 2015). The fact/value dichotomy is rooted in philosophy. 
Socrates asked his pupils if they believed in something or if they knew something. Since then, "knowing" has been imbedded in realism, whereby assertions described the world as it is, whereas beliefs are the mere expression of a given opinion. Of course, the epistemology behind Plato or Aristotle has long been criticized and was replaced by the epistemology of science in the twentieth century. The modern version of the fact/value dichotomy can be traced in the Vienna Circle (1923). The anti-metaphysics stance held an empiricist criterion of meaning. Basically, this signifies that any statement that cannot be verified by an empiricist criterion is meaningless. From that point of view, ethics and esthetics have no objectivity and are considered subjective to the speaker. This assertion may explain why the clash between background concepts of what is "verifiable" or "unverifiable" in HTA reproduces the fact/value dichotomy that has confronted philosophers about the nature of science and ethics for the first half of the twentieth century.

The task of integrating ethics in the HTA process requires revisiting this fact/value dichotomy in such a way that a bridge can be built between the various academic disciplines involved in the HTA assessment process. The challenge for philosophers is therefore to explain how the fact/value dichotomy has been criticized in such a way that it can no longer rest solely on the simple distinction between "verifiable" and "unverifiable" However, such undertaking can be only be effective if one starts by clarifying the different accounts of this dichotomy and the reasons given by philosophers to demonstrate its weaknesses (1. Revisiting the fact/value dichotomy). Given that each account and criticism rest on background concepts, it is important to show how the speech act approach may shed new light on the debate around such dichotomy (2. Speech act approach: assertion, evaluation and prescription). In light of the speech act approach, it will then be possible to show how assertion, evaluation and prescription can be articulated in HTA assessments (3. Beyond the fact/value dichotomy in HTA).

\section{Revisiting the Fact/Value Dichotomy}

What does it mean to distinguish "verifiable" from "unverifiable"? Usually, the distinction seems to refer to "what is objective" and "what is subjective". As Putnam pointed out: "the idea that 'value judgements are subjective' is a piece of philosophy that has gradually come to be accepted by many people as if it were common sense" (Putnam, 2002). According to this reasoning, judgments of facts are considered "objectively true" and capable of being "objectively warranted", while value judgments cannot. Considering the binary mode of such distinctions, this account of the dichotomy claims that what is not "objective" is necessarily "subjective". The link between what is objective and what is verifiable is clear according to the logical positivism's point of view where judgments can either be synthetic (verifiable) or analytic (true by logical rules) while other types of judgments such as those found in ethics, metaphysics and aesthetic cannot be true or false. The background concept of logical positivism not only has to do 
with what is considered to be true or false, but it also extends this distinction to what is cognitively meaningful or meaningless (Putnam, 2002). Accordingly, the utterances from ethics, metaphysics and aesthetics are statements without cognitive meaning and must be, therefore, associated with feelings and/or emotions.

Questions aimed to ask: "what is a fact" and how a "fact" is or not verifiable opens up a first breach in the fact/value dichotomy. For Hume and the original positivists, "facts" can be verified by observation or sensory experience (Putnam, 2002). Stephen Toulmin's account of "properties" (Toulmin, 1950) clarifies the change in the background epistemological concepts having to do with the very notion of facts. In other words, judgment of facts attributes properties to objects. Toulmin distinguishes three types of properties: simple qualities, complex qualities and scientific qualities. Simple qualities are those that are attributed to an object, e.g. asserting that a given object is red. They are considered part of the object itself and verifiable by our senses. Such properties are directly verifiable and cannot be analyzed. Complex qualities can also be verified by our senses but need to apply a criterion. Taking Toulmin's example that a regular polygon is 259 sided presupposes the operation of actually counting the sides. Therefore, complex properties can be analyzed. Alternatively, scientific qualities are properties that are attributed to an object by virtue of a scientific theory, so they are not verified by observation and sensory experience. Scientific qualities therefore turn out not to be "facts" as they are defined by Hume. More important, such qualities are needed expressly to clarify the limits of simple properties attributed by observation and sensory perception. Is a stick in the water really bent? Is the setting sun really red? In these cases, scientific theory can warrant the fact that the stick is really straight and that the sun is really yellow, based on refractive indexes in both cases, even though our eyes perceive them differently.

The relationship between facts, qualities and verification is basically moulded on the epistemological correspondence theory of truth, which more precisely proposes that knowledge is a description of the world and that every statement that has a meaning corresponds to the structure of the world itself. As Putnam suggests: "But science had changed radically since Hume's day, and the positivists found themselves pressed more and more to abandon their initial notion of fact, which was somewhat similar to Hume's, in order to do justice to the revolutionary science of the first half of the twentieth century" (Putnam, 2002). In other words, the "realism" imbedded in the correspondence theory of truth, claiming that a verified statement corresponds to the very structure of reality, has been abandoned for a more complex relationship between science and reality as proposed by W. V. Quine (Quine \& Ullian, 1970). Without realism, however, the correspondence theory of truth cannot provide an "objective" status to "facts".

A second breach in the fact/value dichotomy comes from the reasons given for restricting the meaning of a statement to what can be verified. In the fact/value dichotomy, only statements can harbour a meaning and a statement is defined as a proposition that states a fact (Dictionary.com, 2018). This is why any utterance that is not a statement cannot have a meaning. The background 
concepts implied bring us to consider a statement as a specific way of saying something, thus limiting it to a descriptive component. Putnam raises the question about the following assertion, "he is very cruel" (Putnam, 2002). Is this a statement having descriptive meaning or not? The answer to this question rests on the nature of the quality of the word "cruel". Is "cruel" a simple quality verified by our senses? If not, is it a complex quality implying the use of a criterion? Of course, when the qualifier "cruel" is given to someone, different criteria can be monopolised, but contrary to the complex qualities defined by Toulmin, the criteria for "cruel" are not the same as that of a polygon. In fact, in the later, sides can actually be counted as in the former; there exists different degrees in "cruelness". Is "cruel" a scientific quality attributed by virtue of a scientific theory? Should we have to conclude that the saying "he is very cruel" is not a statement and, therefore, meaningless?

Such a conclusion seems to contradict our everyday experience of language. Such utterance conveys a certain meaning but which meaning? For the proponents of the fact/value dichotomy, such utterance expresses the feelings of the utterer on the object. Toulmin defines this as the "subjective approach" in ethics: "in saying that anything is good or right, we are reporting on the feelings which we (or the members of our social group) have towards it" (Toulmin, 1950). The subjective approach classifies all ethical properties, like good, to properties like pleasant and satisfying, and so the only meaning they have is to report a subjective attitude towards the object. Of course, if one says of someone that "he is very cruel", this person expresses clearly a dislike of the other person, but is this all this person says? Imagine a dialogue between two friends where one says, "That film was pleasant" and the other, "Not for me, it was unpleasant". Can the dialogue continue? If one of them ask the other "Why was it pleasant or unpleasant?" what can be added? Nothing but repeating it in different words: I liked it, or I didn't like it. Under the assumptions of the subjective approach, ethical utterances are thus reduced to reporting personal preferences.

According to this reduction of ethical qualities to personal preferences, the utterance "he is very cruel" would only convey the meaning "I dislike him". But doesn't this contradict our everyday use of language? If someone says "he is very cruel", this person is saying more than that he dislikes the other person and he should be able to make explicit why he can award the attribute of "cruelness" and to what degree (i.e. very) to the person being evaluated. In other words, the attribution of ethical qualities can only be done if there are reasons to back it up. A revised version of the subjective approach takes into consideration that ethical utterances are more than the mere reporting of feelings and consider ethical utterances as made up of two components: descriptive and attitudinal. Putnam's summarizes Hare's position as follows: "To claim that the thick ethical concepts are 'factorable' into a purely descriptive component and an 'attitudinal' component. The descriptive component then states the matter of fact that the predicate corresponds to, and the attitudinal component expresses an 'attitude' (i.e. an emotion or volition) exactly as in noncognitivist accounts if the function of 
'good', 'ought', and so on" (Putnam, 2002). In such an approach, the descriptive component by which the attribute is given to the object is not directly related to the attitude or emotion conveyed in the utterance. In other words, the descriptive content cannot be a reason for the attitude towards the object.

Another account of the fact/value dichotomy is that it focuses more on the impact of the utterance than its components. The meaning of ethical utterances is related to the function of the utterance in a speech context. In this account, it is the very nature of attributing an ethical quality to an object that is considered to be meaningless. The preceding accounts of the fact/value dichotomy take into consideration the identical structure of utterances attributing simple or complex qualities to an object: "the apple is red" and "the apple is good." Under the subjective approach, the difficulty lies in the identical structure of attributing a quality to an object. Since ethical qualities cannot be verified as done for descriptive properties, the differences can be spelled out by the reduction of the meaning to the expression of feelings. For the "Imperative approach", as Toulmin names it, the error of the preceding interpretations lies in the fact that they consider ethical utterances on the same ground as do statements to attribute a quality to an object. Toulmin presents Ayer's position as follows: "In contrast to those sentences of the form 'So-and-so is X', which give information of some kind, the whole force of ethical statements (according to him) is rhetorical' (Toulmin, 1950). In the imperative approach, statements can convey information about something in the form of so-and-so is X or take different forms in order to have an impact on the listener's beliefs or attitudes towards something.

The criticism of the fact/value dichotomy by Putnam and Toulmin shows that the background approach to the dichotomy has changed from an epistemological perspective (statement of facts being verifiable whereas value judgments are unverifiable) to a propositional perspective (so-and-so is $\mathrm{X}$, where descriptive properties can be verified while ethical qualities are expression of feelings), and finally to a language perspective (the force of assertions for facts and imperatives for values). This change is attributable to the evolution of philosophical inquiry in philosophy of science since Hume's distinction of fact and value.

The main critique of the fact/value dichotomy concerns the notions of reason and meaning. For the proponents of the fact/value dichotomy, giving reason to saying that "so-and-so is X" can only be done by verification of the existing property of X. Only verification can account for giving reason to the statement. As we have seen, the background concepts of such a definition of giving reasons rests on the empirical premises of logical positivism. Amongst them, the verifiable theory that is grounded into "realism", which claims that the structure of scientific statements reproduces, according to the correspondence theory of truth, the structure of reality. Do scientists nowadays still give credence to the realism theory? But if we abandon "realism" in science, the differences between "So-and-so is X", (X being either a scientific quality or an ethical quality) is not a dichotomy, but just a different way to give reason to the attribution of a quality to something. Both Putnam and Toulmin insist that what is fundamentally at 
stake here is the place of reason in ethics. But to understand the place of reason in ethics as in science, one has to take into account the very nature of meaning.

The fact/value dichotomy paradigm primarily rests on the conception that a meaning is related to propositions, which states the matter of a fact. This definition of meaning is then reduced to the information that a statement conveys when it is verified. Propositions other than statements are, therefore, without meaning. Such a restrictive definition rests on background concepts of language and its functions. The imperative approach draws a clear line between assertions and other forms of language having an imperative rhetorical force. As Putnam's example of "He is very cruel" shows, such an utterance cannot be attributed to either assertion or imperatives. Guided by a linguistic approach of ordinary language, Toulmin stresses that the meanings of propositions are clearly connected with the kind of activity in which they are expressed. In other words, meaning in scientific activity may be expressed in terms of verification or non-falsifiable matter but such meaning is then limited to this activity. When considering ethical propositions, one has to consider their meaning in the activities in which they are referred. "The key of the logic of ethical arguments and sentences is to be found in the way in which we come to allow reasons to affect our choice of actions" (Toulmin, 1950).

Since the fact/value dichotomy ultimately rests on a background concept of the function of language in specific activity contexts, revisiting the fact/value dichotomy in the light of the speech-act theory can provide a better understanding of the functions of assertions, evaluations and commands, involved in the fact/value dichotomy.

\section{Speech Act Approach: Assertion, Evaluation and Prescription}

In 1955, J.L. Austin presented at the William James Lectures his approach to understand the different functions of language. He entitled his lectures: "How to do things with words" (Austin, 1962). What things can be done by saying something to someone? To answer this question, Austin develops the notion of what "force" language exerts on the hearer. As we have seen in the fact/value dichotomy, meaning what we are saying to someone was classified either as giving information about something or directing people's actions by a rhetorical force referred to as imperative. For Austin, saying something to a listener conveys three different "forces" through different speech acts: the locutionary, illocutionary and perlocutionary acts. The locutionary act (Austin, 1962) consists of 1) making certain sounds, 2) using a certain vocabulary structured grammatically in a given language and 3) using both preceding acts to mean something to the listener. The illocutionary act is the act of using a locutionary act in a certain way. In the speaker-listener relationship, one may use a locutionary act for different purposes. The locution "The cat is on the mat" can be used: to ask a question "Is the cat on the mat?", to assert something "the cat is really on the mat", to command something "put the cat on the mat", etc. Illocutionary acts are not "rhe- 
torical forces"; they are imbedded in the language conventions. The rhetorical force of locutionary and illocutionary acts is called a perlocutionary act. "Saying something will often, or even normally, produce certain consequential effects upon the feelings, thoughts, or actions of the audience, or of the speaker, or of other persons" (Austin, 1962).

In the speech act approach that uses language in a speaker-listener relationship, illocutionary acts have a particular status, since some of them are considered as performing something rather than stating something (Austin, 1962). "I promise to do x", "I order you to do x" and "I declare you husband and wife" are illocutionary acts that actually do something in human interactions based on the conventions of the language utilized. When I promise, I create an obligation to do something and if I don't respect the obligation, I can be blamed for it. When I command, I create an obligation to the subordinate to do as commanded and if not, he is liable to be blamed. When one declares people husband and wife, he changes the status of the persons and their mutual obligations. Of course, to be effective these performatives must follow certain rules (Austin, 1962). For instance, someone cannot command someone else if the former does not have the authority on the subordinate as well as he/she cannot marry people if he/she does not have the legal authority to perform weddings.

Promising and commanding are two performatives forms that can help us understand the relation between obligations and reasons. Take the following discussion: A says to B "You have the obligation to do X" and B replies "I have not". How can these conflicting statements be resolved? In order to render explicit the reasons for the existence of a given obligation, one must refer to the performative that created the obligation. A can then say to B: "The obligation exists because you promised to do so". But B can reply to A: “I didn't promise, I just said that I had the intention to do so". A and B could then have the same discussion about obligations resulting from commands.

In certain conceptions of moral or of law based on commands, the obligations are created by God or by Parliament; in other words, by an authority recognized as capable of issuing commands. Here again, in order to recognize that one has an obligation resulting from a given command, one must a priori recognize the authority of the commander. Many writings in philosophy and religion are aimed at providing reasons to ground the authority of moral obligations because the existence of the obligation for a speaker depends indeed on his recognition of such authority.

The performatives of promising and commanding clarify the use of prescription as a mean to guide conduct but there are other illocutionary acts that pertain to conduct without referring to obligations such as warning, advising and recommending. If one says "stop smoking", this person may be warning or advising or recommending someone else. The conventional effects are different. To warn is to give a forceful and cautionary advice, to advise is to counsel someone on a course of action, and to recommend is to convey something as worthy of doing. 
Declaratory performatives, as we have seen, are not conventionally related to a course of action but rather to a state of affairs. To declare two persons husband and wife, to declare an accused guilty, or to declare war are performatives that create a new state of affairs. These resemble promising and commanding in the field of behavior. There are also other illocutionary acts like assertions or reports that concern giving information on a state of affairs. Assertion by convention is saying that something is true. It is the illocutionary act corresponding to a statement. Assertions are the only illocutionary acts that are referring to truth. Just as judgments of facts are expressed by assertions, value judgments take the form of "evaluations". By linguistic convention, evaluating aims to determine or set the value of something. Every professor or teacher knows that his evaluation of a student's paper can be criticized, and he must give reasons to the student in order to justify it.

Austin never considered the judgment of values on the same grounds as that of facts. Of course, he did not claim the pretentiousness of treating every illocutionary act. But considering the importance of values in applied ethics today, we can ask ourselves if a speech act approach for the judgements of values can help us understand the very function of values in ethical discourse.

Evaluating determines the quality of something: "This is a very good paper" or "This isn't good at all." The question this raises is: can evaluations be right or wrong? To answer this, one is confronted with the comparison of the meanings of "so-and-so is red" and "so-and-so is good". As Toulmin has shown, the objective theory in ethics claims that evaluations are subject to be true or false. For them, the goodness is a property like red and therefore the correspondence theory of facts applies to evaluations. But if evaluations are assertions, then the debate focuses on the reasons given to claim that the evaluation is true. To be effective, the speech act of assertion must have a shared procedure to determine the truth of an assertion. As we have seen it the fact/value dichotomy, the scientific proof for the assertion that a stick in the water is not bent cannot be applied to evaluations. For proponents of the objective theory in ethics, evaluations can be true or false with another type of proof than a purely scientific one.

Evaluating and asserting may have the same structure of "so-and-so is X" but their respective illocutionary acts are different. Whereas an evaluation sets the value of something, an assertion states that something is true. Even if both have the same structure, these illocutionary acts are different. In an assertion, the property $\mathrm{X}$ is recognized as part of so-and-so, while in an evaluation the quality $\mathrm{X}$ is attributed to so-and-so. In other words, while qualities are ascribed to things, properties are rather recognized as an intrinsic part of the thing. It is the ascription of a quality that is specific to evaluation. Assertions, as we have seen in the fact/value dichotomy, are considered true or false if they correspond or not to the state of affairs they refer to. But an illocutionary act can be questioned by the listener: "Is this really true?" "Why do you recommend this?" "Is this really good?" In other words, reasons must be specified to a given listener in order to accept the illocutionary act. Any illocutionary act is open for debate so giving 
reasons turns out to be a necessary component of any speech act. Therefore, the listener can ask for the reasons that justify the ascription of a quality in an evaluation. The justification of criteria is about its nature, the number of criteria used, the priority given to each criterion and their application. Evaluations are not the mere statements of preferences (which are self-referenced), because their validity as a speech act implies giving to the listener the reasons that warrant them.

From a speech act approach perspective, the dichotomy between facts and values totally collapses. First of all, assertions do not have a unique position in the uses of language, because it is just one illocutionary act among others. "By the same token, the familiar contrast of 'normative and evaluative' as opposed to factual is in need, like so many dichotomies, of elimination" (Austin, 1962). Second, the proponents of the fact/value dichotomy consider only two "forces" in the use of language, the proposition force of statements and the rhetorical force of all propositions other than statements. The speech act theory shows that the use of language involves three different types of forces, locutionary, illocutionary and perlocutionary. Every locutionary and illocutionary act may be used to have rhetorical force. Assertions can have different perlocutionary effects, as political campaigns illustrate. Finally, a speech act approach clarifies the necessity to provide reasons when the illocutionary act is criticized. The fact that one can be: giving reasons to justify the existence of a moral obligation, giving reasons to justify an evaluation or giving reasons to justify the truthfulness of an assertion, clearly shows that reasons are not limited to being used solely in assertions. Giving reasons for prescriptions, warnings, advices and recommendations will necessarily imply both evaluations and assertions. Giving reasons to evaluations will also imply making assertions when applying a given criteria to the object being evaluated. Giving reasons for assertions thus implies evaluating the quality of proof between different epistemic approaches.

\section{Beyond the Fact/Value Dichotomy in HTA}

The fact/value dichotomy in HTA is usually concentrated on two aspects: the epistemological gap between different types of analysis and the integration of different types of analysis in the HTA process. At the epistemological level, Refolo et al. identify the main source of this gap in the domains of the analysis, some of which are relevant to natural sciences, like safety and effectiveness, while others pertain to humanistic domains like ethical, legal and sociocultural (Refolo et al., 2016). More than the domains of the analysis, it is the very nature of the inquiry itself that highlights such gap: "To sum up, current HTA configuration is predominantly based on the comparison among objective and empirically testable 'facts', whilst ethics is not empirically testable" (Refolo et al., 2016). While for the authors, testable facts yield "objective information" (Refolo et al., 2016); the non-testable approach is nevertheless not named as subjective.

A full HTA should, in principle, cover different aspects of the technology besides effectiveness and safety like cost-effectiveness, ethical, legal and social implications. How can such analysis, based on different methodological approach- 
es, be integrated in a final report? Here again, the fact/value dichotomy emerges, but this time labelled as the distinction between assessment and appraisal: "Health technology assessment has traditionally been based on such a distinction between facts and values. The gathering, systematizing, and synthesizing of information has been considered as the factual (assessment) part and the appraisal of this information as part of or preparing a decision-making process has been considered to be an issue of value (evaluation)" (Hofmann, Bond, \& Sandman, 2018). The distinction between assessment and appraisal may have different interpretations. According to Martin et al., the assessment corresponds to the first phase where all scientific information is collected including effectiveness, safety and cost-effectiveness analysis, while the appraisal phase corresponds to contextualised studies and recommendations (Martin, Williams-Jones, \& de Ortúzar, 2011). In this perspective, the fact/value dichotomy seems to refer to non-contextual (universal) versus contextual (local) studies. Furthermore, local studies in which ethical, legal and social issues are raised seem to be fundamentally linked to the recommendation process and not to that of the assessment. But for Burls et al. "While this scientific/value distinction may be helpful for defining roles, it does not, and should not, preclude ethical analysis in the assessment process" (Burls et al., 2011). For others, assessment differs from appraisal because there is a prescriptive aspect in the recommendations made (Refolo et al., 2016). Appraisal is necessarily linked to a policy-making level where values become a necessary component (Hanvoravongchai, 2008).

Can a clear-cut distinction between assessment and appraisal really pass the test when one takes into consideration the social role of HTA? The claim for the objectiveness of the assessment rests on the idea that an analysis made by empirical methods is the only one capable of making assertions. This is why the other analyses should be considered differently as evaluations or prescriptions, which are only to be discussed in an appraisal phase. Since the distinction between assessment and appraisal varies according to authors cited above, the relations between assertions, evaluations and recommendations are more complex than was presupposed. Furthermore, everyone agrees the principal aim of HTA is to help decision-makers. The assessment input has been recognized: "One of the main strengths of HTA is its great 'ability' to provide empirical evidence in order to support the decision-making" (Refolo et al., 2016). But how can empirical evidence support decision-making? If assessments can help a decision-maker, they must implicitly make an evaluation of the "evidence" produced and such an evaluation may guide the decision-maker only if it contains an implicit recommendation (Sandman \& Heintz, 2014). To understand the relationship between assertions, evaluations and prescriptions in HTA, we must start with an analysis of the very nature of each analysis.

What is an analysis of effectiveness? When one is saying that "so-and-so is clinically effective" is he asserting something or is he evaluating something? An assertion, undertaken as a speech act, is the description of a property, while an evaluation is the ascription of a property. Is effectiveness the same as the colour 
white, something that can be recognised by an objective description? No, because to say that something is effective is to attribute to the object a property by the use of certain criteria. In other words, to say that "so-and-so is clinically effective" is an evaluation, not an assertion. In HTA, clinical effectiveness is the first criterion used in effectiveness analyses. But in order to perform a thorough analysis, more criteria are needed. Different definitions of clinical effectiveness show how each analysis are dependent on the choice of criteria and on the modes of application chosen for such criteria. According to the medical dictionary: "Clinical effectiveness is a process measured by the number of lives saved, or by improvements of objective parameters of a morbid condition" (Farlex, 2018). The choice of objective criteria to evaluate the clinical effectiveness explains why the analysis tends to concentrate on empirical studies, which can show if there are or not improvements associated to the use of the technology at stake. However, it is not because an evaluation is based on objective criteria that it changes the evaluation into an assertion. For the European Patient's Academy, clinical effectiveness is defined as "a component of a dossier submitted for HTA assessment," it "is a measure of how well a particular treatment works in the practice of medicine. It depends on the application of the best knowledge derived from research, clinical experience, and patient preferences" (Eupati, 2018). In such a definition, the criteria are the qualitative effects (how well a particular treatment works) and this is applied to the practice of medicine. The information gathering required to apply these criteria are directly related to their nature. This is why the best knowledge derived from research is just one source of information. Clinical experience and patient preferences constitute other sources, which are also required.

The same logic applies to safety analysis. The property of safety is attributed to something by means of criteria. To say that something is safe means that it does not produce harm. But in order to attribute safety to a technology, one needs more criteria. Of course, a toxicological criterion or any other criteria having a biological significance can be chosen, but there remains, however, other types of impacts that can harm someone. Thus, the quality of the information gathering will inevitably vary according to the criteria used.

A cost-effectiveness analysis necessitates the fusion of two separate evaluations: cost and effectiveness. This is at the heart of the notion of Quality Adjusted Life-Year (QALY): "A measure of the state of health of a person or group in which the benefits, in terms of length of life, are adjusted to reflect the quality of life. One QALY is equal to 1 year of life in perfect health. QALYs are calculated by estimating the years of life remaining for a patient following a particular treatment or intervention and weighting each year with a quality-of-life score (on a 0 to 1 scale). It is often measured in terms of the person's ability to carry out the activities of daily life, and freedom from pain and mental disturbance" (NICE, 2018). A cost-effectiveness comparison between two technologies would show that for an equivalent or cheaper cost, the number of "QALY" is similar or superior to one over another. The data from different studies both quantitative 
and qualitative is required to reach a conclusion in a cost-effectiveness analysis.

Ethical analysis, prima facie, is a procedure that is, by definition, evaluative. But when ethical analysis aims to set the ethical issues debated in society, isn't it a descriptive approach necessary to account for sociocultural facts? The Haute Autorité de Santé (HAS), in France, proposes a methodological guide for ethical analysis (Haute Autorité de Santé HAS, 2013), which aims to provide a "descriptive" of the actual debates in society around the technology to be evaluated. Arguments for and against a given technology are to be gathered from different social sources of information.

The HTA Core model presents different norm based-approaches used by HTA agencies as methodologies for ethical analysis, namely: casuistry, principlism, social shaping of technology, the Triangular model based on a human person-centered approach and an Axiological (Socratic) approach. In some approaches, the ethical analysis is centered on "prescription" more than on "evaluation". Norm-based analysis focuses on compliance or not to a norm. Axiology on the other hand focuses on evaluating the impacts of a technology. Ethical analysis necessarily implies evaluation but what about the other types of analysis found in HTA processes?

Effectiveness, safety, cost-effectiveness which many consider assertions are, as we have shown above, relative evaluations. In each case, the result of the analysis attributes a quality to a technology by the use of criteria. For each quality attribution there is a choice of criteria, a priority setting and a mode of gathering information to apply the criteria to the technology at stake. But, if the evaluative structure is assumed to be the same, why is the fact/value dichotomy still discussed in the HTA literature? Primarily for one reason: the power of truth. In the fact/value dichotomy, fact is opposed to value as much as objective may be opposed to subjective, and what is objective can either be true or false. There is still a realistic stance imbedded in the idea that scientific methodology can always find what is objective. What is objective thus remains construed as if scientific methodology gives descriptions of the world that are true or false and interpreted as they are not the result of qualities attributed on the basis of scientific criteria. Remnants of the fact/value dichotomy also appear when references are made to patient preferences. The widely used expression "patient preferences" refers basically to a private emotional state of liking something. But, as we have seen earlier, there is quite a difference between stating, "I like this" and "I evaluate positively this treatment because of so-and-so".

Abandoning the standards of scientific realism is the last step towards the total downfall of the fact/value dichotomy. But, if scientific realism isn't true anymore, does this mean that scientific methods are no better than any other methods? Since Socrates, philosophers have tried to distinguish "belief" and "knowledge"; a belief is a personal opinion on something while knowledge is "a body of facts learned by study or experience" (Merrian-Webster, 2018). This notion is at the root of the fact/value dichotomy. But as the pragmatic philosophers of science such as Quine and Ullan have shown, we are always in the web of be- 
liefs; the full question is how to deal with them in our lives. In other words, what role do "reasons" play in our beliefs? "Insofar as we are rational in our beliefs, however, the intensity of belief will tend to correspond to the firmness of the available evidence. Insofar as we are rational, we will drop a belief when we have tried in vain to find evidence for it" (Quine, 1978). In the field of HTA, every analysis is an evaluation based on criteria, the application of which depend on assertions, and all these evaluations have a performative force of qualifying something as having value. The force of each of these evaluations rests on the reasons that warrant each of them. But what distinguishes the different analyses in HTA is the way each of these methodologies is proposing a way to ground beliefs into reasons.

\section{Conclusion}

The fact/value dichotomy inherited from the Vienna Circle maintained an airtight distinction between scientific assertions vs other assertions or meaningful vs meaningless in terms of knowledge. With Quine and his pragmatic approach in the epistemology of science and with Austin and his pragmatic speech act approach of language, the fact/value dichotomy was compelled to collapse and the place of reason in ethics was rehabilitated.

A speech act approach brings one to think outside the box of the opposition between knowledge and belief, which is an epistemological paradigm, and to adopt a discursive perspective where saying is exercising a force on a listener. Why do we do HTA, if not to exert a force on the decision-maker? But what kind of force do we want to exert? Decision-makers are confronted with a mass of information originating from different sources such as academia, industry, patient groups, public polls, etc. All this information has a "persuasive" effect, and some are certainly constructed to aim towards this perlocutionary force. Can decision-makers base their decisions solely on the beliefs conveyed by persuasion? It is rather expected that decision-makers will base their decisions on rational beliefs and this is why broader analyses (i.e. contextual) are needed in HTA. Each of these analyses gives different reasons to adopt or not a given technology in the health system.

The current challenge is to synthesize all the results of the analyses based on different criteria and methods of gathering information. The present paradigm in HTA is epistemological: natural sciences for effectiveness and security, behaviorist human sciences for cost-effectiveness and other human sciences for ethics. By initially adopting an epistemological standpoint, the methodology imposes, a priori, the nature of the criteria; their diversity, the priority setting and their mode of application. In the end, it is impossible to integrate such diversification in a holistic evaluation of a technology. We must always consider that every analysis evaluates only certain impacts of a given technology on patients, health practices, health expenditures, etc., and in a specific way, as it has been defined by the criteria. In order to have a more complete picture of the complex- 
ity of the situation, a mapping of the impacts of the adoption of a technology should be at the onset of such analysis. A comparison between the results of the different analyses on these impacts would then be possible. Furthermore, making reasons that warrant the results explicit will allow the discussions to determine their justifications and thus improve their validity. Ultimately, the recommendation that follows can explicitly guide the decision-maker.

When decision-makers decide to adopt a health technology, by considering all the impacts, they are actually endorsing a way of life for people concerned. And by choosing this way of life instead of another, they consider it the best way possible. Their rationale is grounded on reasons that validate it. Such an appeal for making reasons that ground the decision-makers' decision explicit is more effective than giving a logical argument, it is a way of giving force and meaning to the choice made on behalf of all those who have a stake in it and are being impacted by the decision.

\section{Acknowledgements}

The authors wish to thank Ms. Louise Corbeil for editorial work on the manuscript.

This work was supported by the Canadian Institutes of Health Research (J.P., grant number 142187).

\section{Conflicts of Interest}

The authors declare no conflicts of interest regarding the publication of this paper.

\section{References}

Assasi, N., Schwartz, L., Tarride, J. E., O’Reilly, D., \& Goeree, R. (2015). Barriers and Facilitators Influencing Ethical Evaluation in Health Technology Assessment. International Journal of Technology Assessment in Health Care, 31, 113-123. https://doi.org/10.1017/S026646231500032X

Austin, J. L. (1962). How to Do Things with Words. Cambridge: Harvard University Press.

Burls, A., Caron, L., Cleret de Langavant, G., Dondorp, W., Harstall, C., Pathak-Sen, E., \& Hofmann, B. (2011). Tackling Ethical Issues in Health Technology Assessment: A Proposed Framework. International Journal of Technology Assessment in Health Care, 27, 230-237. https://doi.org/10.1017/S0266462311000250

Dictionary.com. (2018). Definition of Stated.

Eupati (2018). European Patients'Academy. https://www.eupati.eu/?s=clinical+effectiveness

European Network for Health Technology Assessment EUnetHTA (2014). HTA Core Model $^{\oplus}$ Online, Version 2.1 edn. Helsinki: National Institute for Health and Welfare.

Farlex (2018). The Free Dictionary.

Hanvoravongchai, P. (2008). Health System and Equity Perspectives in Health Technology Assessment. Journal of the Medical Association of Thailand = Chotmaihet Thangphaet, 91, S74-S87. 
Haute Autorité de Santé HAS (2013). Assessment of Ethical Aspects. https://www.has-sante.fr/portail/upload/docs/application/pdf/2014-11/assessment_of_ ethical_aspects.pdf

Hofmann, B. M., Bond, K., \& Sandman, L. (2018). Evaluation Facts and Facting Evaluation: On the Fact-Value Relationship in HTA. Journal of Evaluation and Clinical Practice, 24, 957-965. https://doi.org/10.1111/jep.12920

HTAi (2018). HTAi: About HTAi. http://www.htai.org/index.php?id=428

Legault, G. A., Patenaude, J., \& Parent, M. (2010). Les Comités d'éthique de la recherche sur l'humain: Les chercheurs face aux enjeux d'internormativité et de gouvernance. Revue de droit de l'Université de Sherbrooke, 40, 383-407.

Legault, G. A., Verchères, C., \& Patenaude, J. (2018). Support for the Development of Technological Innovations: Promoting Responsible Social Uses. Science and Engineering Ethics, 24, 529-549.

Martin, C., Williams-Jones, B., \& de Ortúzar, M. G. (2011). Ethical Health Technology Assessment in Latin America: Lessons from Canada and Argentina. Acta Bioethica, 17, 225-236. https://doi.org/10.4067/S1726-569X2011000200009

Merrian-Webster (2018). Merrian-Webster Thesaurus.

NICE (2018). NICE Glossary. https://www.nice.org.uk/glossary?letter=q/Quality-adjusted

Patenaude, J., Legault, G.-A., Bernier, L., Beauvais, J., Béland, J.-P., Boissy, P., \& Tapin, D. (2015). Framework for the Analysis of Nanotechnologies' Impacts and Ethical Acceptability: Basis of an Interdisciplinary Approach to Assessing Novel Technologies. Science and Engineering Ethics, 21, 293-315. https://doi.org/10.1007/s11948-014-9543-y

Putnam, H. (2002). The Collapse of the Fact/Value Dichotomy and Other Essays. Cambridge, MA: Harvard University Press.

Quine, W. V. (1978). The Web of Beliefs (2nd ed.). http://socialistica.lenin.ru/analytic/txt/q/quine_1.htm

Quine, W. V., \& Ullian, J. S. (1970). The Web of Belief. New York: Random House.

Refolo, P., Sacchini, D., Brereton, L., Gerhardus, A., Hofmann, B., Lysdahl, K. B., \& Spagnolo, A. G. (2016). Why Is It so Difficult to Integrate Ethics in Health Technology Assessment (HTA)? The Epistemological Viewpoint. European Review for Medical \& Pharmacological Sciences, 20, 4202-4208.

http://ovidsp.ovid.com/ovidweb.cgi?T=JS\&CSC=Y\&NEWS=N\&PAGE=fulltext \&D=pr em\&AN=27831656

Sandman, L., \& Heintz, E. (2014). Assessment vs. Appraisal of Ethical Aspects of Health Technology Assessment: Can the Distinction Be Upheld? GMS Health Technology Assessment, 10, Doc05.

Toulmin, S. E. (1950). An Examination of the Place of Reason in Ethics. Cambridge, MA: Cambridge University Press.

WHO-HTA (2017). WHO: Medical Devices.

http://www.who.int/medical_devices/assessment/en/ 